\section{Cotinine: an Oxidation Product of Nicotine formed by Rabbit Liver}

A MAJOR advance in the elucidation of nicotine metabolism was the demonstration by McKennis et $a l .1$ that dogs receiving nicotine excreted small amounts of $\gamma$-(3-pyridyl)- $\gamma$-methylaminobutyric acid and its lactam, cotinine. These workers favoured the view that cotinine was formed in urine by spontaneous lactamization of the acid. However, they also suggested that cotinine might be an intermediate in nicotine metabolism which was hydrolysed to the acid in vivo.

We have previously reported ${ }^{2}$ that nicotine is metabolized in liver microsomes by an enzyme system requiring reduced triphosphopyridine nucleotide and oxygen. We now wish to report that a major product of nicotine oxidation by liver preparations is cotinine.

3 umoles of nicotine were incubated with a supernatant fraction of rabbit liver (prepared at $9,000 \mathrm{~g}$ ), supplemented with triphosphopyridine nucleotide $(0.5 \mu \mathrm{mole})$, glucose-6-phosphate (25 umoles) and nicotinamide $(0.1 \mu$ mole $)$, for $90 \mathrm{~min}$. at $37^{\circ} \mathrm{C}$. under oxygen. Unchanged nicotine was extracted into heptane and assayed spectrophotometrically (259 $\mathrm{m} \mu$ in $0.1 \mathrm{~N}$ hydrochloric acid). Cotinine remaining in the aqueous phase was then extracted into chloroform. After washing with $0 \cdot 1 M$ citrate buffer, $p \mathrm{H} 5 \cdot 0$, to remove an unidentified metabolite, the chloroform phase was extracted with $0.1 \mathrm{~N}$ hydrochloric acid. Material in the acid phase, accounting for about half the metabolized nicotine, was tentatively identified as cotinine by ultra-violet absorption ( $\lambda_{\max } .262 \mathrm{~m} \mu$ ), comparative distribution ratios ${ }^{3}$ and paper chromatography with three solvent systems.

The metabolite was isolated as follows : nicotine $(1,200 \mu$ moles $)$ was incubated with $1,200 \mathrm{ml}$. of liver supernatant fraction and other components in proportion. Cotinine was extracted into chloroform as described above and the organic phase washed with citrate buffer, $p H \mathbf{H} \cdot 0$. After evaporation of the chloroform at room temperature under nitrogen, the residue was subjected to an eight transfer countercurrent distribution between equal volumes of chloroform and $0.6 M$ citrate buffer, $p H 3 \cdot 5$. Contents of tubes 3-6 containing material of similar partition ratios were pooled, alkalinized and the total basic material extracted into the chloroform phase. The chloroform was evaporated and the residue taken up in ether. After drying the ether phase with sodium sulphate, addition of 60 per cent perchloric acid in ethanol $(1: 1)$ gave the perchlorate derivative, m.p. $218-219^{\circ}$. The melting point was not depressed on admixture with authentic cotinine perchlorate ${ }^{4}$, m.p. 218-219 . Analysis-calculated for $\mathrm{C}_{10} \mathrm{H}_{13} \mathrm{~N}_{2} \mathrm{O}_{5}: \mathrm{C}, 43.41$; $\mathrm{H}$, 4.74 ; found: $\mathrm{C}, 43.62 ; \mathrm{H}, 5 \cdot 01$. The infra-red spectrum (in potassium bromide pellet) was identical with that of authentic cotinine perchlorate.

When $15 \mathrm{mgm} . / \mathrm{kgm}$. of nicotine were administered intramuscularly to rabbits, small amounts of cotinine equivalent to about 10 per cent of the dose were excreted in the urine. Similarly, less than 10 per cent of cotinine administered to rabbits $(15 \mathrm{mgm} . / \mathrm{kgm}$. intravenously was found in the urine. Since only small amounts of cotinine are excreted after administering nicotine or cotinine, it is possible that the latter compound is a major metabolite of nicotine in vivo.

It seems possible that the first step in the oxidation of nicotine is hydroxylation, followed by oxidation to cotinine and hydrolysis as follows :
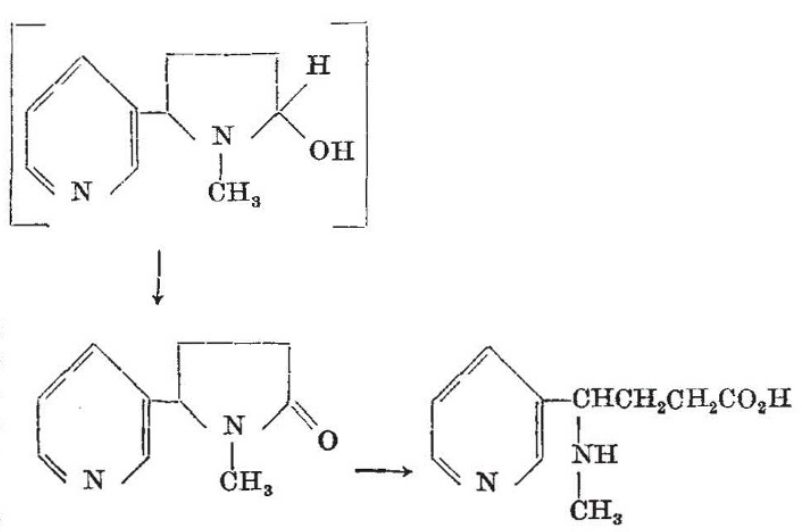

Howard B. HuCker

James R. GILLetTte

Bernard B. Brodie

Laboratory of Chemical Pharmacology, National Heart Institute,

National Institutes of Health. Public Health Service,

U.S. Department of Health, Education and Welfare, Bethesda, Maryland.

$$
\text { Oct. } 23 .
$$

'McKennis, jun., H., Turnbull, L. B., Wingfield, jun., H. N., and Dewey, L. J., J. Amer. Chem. Soc., 80, 1634 (1958).

${ }^{2}$ FHucker, H. B., J. Pharmacol. Exp. Therap., 122, A, 33 (1958). ${ }^{3}$ Brodie, B. B., and Udenfriend, S., J. Biol. Chem., 158, 705 (1945). "Pinner, A., Chem. Ber., 26, 292 (1893).

\section{Composition of Lipids isolated from the Aorta, Coronary Arteries and Circulus Willisii of Atherosclerotic Individuals}

InVESTIGATIONS of lipid deposits connected with atherosclerosis have usually been concerned with the lipids from the plaques formed in the intima of the aorta ${ }^{1}$. Although the condition of the aorta is a guide to the progress of the disease, dysfunction due to atherosclerosis is most liable to occur in the smaller arteries, especially coronary and cerebral arteries. It has generally been assumed that lipid deposition in these arteries oceurs in a similar way to that in the aorta. If this is so, the composition of the lipids deposited should be approximately the same. Lipids extracted from different atheromatous arteries have been examined in order to test this assumption.

The amount of lipid extractable from coronary or brain arteries is extremely small (as indeed it is for healthy aortas), but methods have recently been developed in this laboratory for the separation of as little as $70 \mathrm{mgm}$. of tissue lipids into phospholipids, sterol esters, triglycerides, free fatty acids and free sterols. The first three groups can then be saponified and the resultant fatty acid mixtures, as well as the 